\title{
Use of the COPD Assessment Test (CAT) to screen for COPD in dairy farmers: AIRBAg study
}

Simon Jan ${ }^{1}$, Marie-Astrid Metten ${ }^{1,2}$, Anthony Chapron ${ }^{3,4}$, Solenne Marette ${ }^{5}$, Ange-Marie Robert ${ }^{6}$, Stéphanie Guillot $^{7}$, Carole Mailloux ${ }^{8}$, Stéphane Jouneau ${ }^{2,9,+}$, Jean-François Viel ${ }^{1,2,+, *}$, on behalf of the AIRBAG research group:

${ }^{1}$ Department of Epidemiology and Public Health, University Hospital, F-35033 Rennes, France

2 Univ Rennes, CHU Rennes, Inserm, EHESP, Irset (Institut de recherche en santé, environnement et travail) - UMR_S 1085, F-35000 Rennes, France

${ }^{3}$ Department of General Practice, Rennes 1 University, F-35000 Rennes, France

${ }^{4}$ INSERM, CIC-1414, Primary Care Research Team, F-35000 Rennes, France

${ }^{5}$ Department of Occupational Pathology, University Hospital, F-35033 Rennes, France

${ }^{6}$ Department of Clinical Research, University Hospital, F-35033 Rennes, France

7 Department of Pulmonary Function Tests, University Hospital, F-35033 Rennes, France

${ }^{8}$ Mutualité Sociale Agricole des Portes de Bretagne, F-35170 Bruz, France

${ }^{9}$ Department of Respiratory Medicine, University Hospital, F-35033 Rennes, France

${ }^{\dagger}$ Equally contributed

\#AIRBAg research group: Jean Barakat, Anne-Laure Barel, Henri-Pierre Baron, Rachel Bassen, Florence Behaghel-Baruteau, Cyril Bernier, Séverine Beyer, Romain Boissel, Vanessa Brault, Graziella Brinchault, Dominique Bureau, Odile Castel, Anne-France Cazuguel, Anthony Chapron, Catherine Decelle-Trochet, Benoît Desrues, Marcel Delaunay, Isabelle Delaunay-Lelièvre, Bruno Eveno, Krisztina Fekete, Lisa Fourmont, Thomas Gouyet, Amandine Guervin, Stéphanie Guillot, Tiphaine Guy, Guillaume Héry, Pauline Hardouin, Anne Hespel, Nathalie Jeffray, Stéphane Jouneau, Yves Koskas, Virginie de Lauzun, Antoine Lebossé, Sandrine Lecot, Carole Mailloux, Solenne Marette, David Marquette, Virginie Martin, Ahmed Merzoug, Hugues Morel, Jean Morer, Patrick Morisseau, Aurélie Oksenhendler, Elisabeth Orhant, Dominique Peron, Mauricette Piguel-Royer, Marie Pinault, Jean-Paul Pousset, Jean-Claude Presle, Patrick Raillard, Bernard Regnault, Ange-Marie Robert, Antoine Séguineau, Anne Sevin, Fanny Thépault, Christian Verger, Jean-François Viel.

Corresponding author: Department of Epidemiology and Public Health, University Hospital, 2 rue Henri Le Guilloux, 35033 Rennes Cedex 9, France.

e-mail: jean-francois.viel@univ-rennes1.fr; telephone number: +33299289827 
Running title: Screening for COPD in dairy farmers

\section{AUTHOR CONTRIBUTIONS}

conceived and designed the study: Jouneau, Viel

participated in the acquisition of data: Jouneau, Marette, Robert, Guillot, Mailloux

analysed the data: Jan, Metten, Viel

interpreted the results: Jan, Metten, Jouneau, Viel

drafted the article: Jan, Metten, Viel

revised the article critically for important intellectual content: Jouneau

All authors read and approved the version to be submitted.

\section{CONFLICTS OF INTERESTS}

The authors report no conflicts of interest. 
2 PROF. STÉPHANE JOUNEAU (Orcid ID : 0000-0002-1949-3461)

3 PROF. JEAN-FRANCOIS VIEL (Orcid ID : 0000-0002-6716-7468)

4

5

6 Article type : Original Article

7

8

9 Abstract

10 Objectives: People at risk of chronic obstructive pulmonary disease (COPD) can benefit from

11 appropriate medical management before severe symptoms appear. This study assesses the value of the

12 COPD Assessment Test (CAT) questionnaire for screening dairy farmers, who tend to be slow or 13 reluctant to seek health care.

14 Methods: During the time period 2012-2017, 2089 randomly selected dairy farmers in Brittany 15 (France) were invited to complete self-administered questionnaires (including the CAT) and to 16 undergo an occupational health check-up using an electronic mini-spirometer and conventional 17 spirometry. Those showing symptoms suggestive of COPD and/or a ratio $\mathrm{FEV}_{1} / \mathrm{FEV}_{6}<80 \%$ were 18 sent to a pulmonologist for further check-up, including spirometry with a reversibility test. 19 Multivariate logistic models based on CAT scores and socio-demographic or work-related factors 20 were developed to predict COPD.

21 Results: The 1231 farmers who underwent the occupational health check-up included 1203 who met 22 the inclusion/exclusion criteria. Pulmonologist identified 16 (1.3\%) cases of COPD. A multivariate 23 logistic regression model (covariates: CAT sum score, on-farm time, BMI, smoking status, free-stall 24 mulching) provided an area under the receiver-operating characteristic curve (AUC) of 0.87 (95\% CI: $250.75-0.98$ ). Using a cut-off of 0.007 gave a sensitivity of $93.8 \%$, and a specificity of $62.4 \%$. Another 26 model that included CAT breathlessness and the same covariates performed marginally better (AUC = $270.88,95 \%$ CI: $0.77-0.98)$.

28 Conclusion: Our predictive models can both benefit dairy farmers by providing early diagnosis and 29 management of their COPD and avoid unnecessary, costly spirometry during screening process.

\section{KEYWORDS}

32 Chronic obstructive pulmonary disease; CAT questionnaire; screening; dairy farmers 
 \\ 1. INTRODUCTION}

36 Chronic obstructive pulmonary disease (COPD) is a major public health concern that could become 37 the fourth leading cause of death world-wide by $2030 .{ }^{1}$ The onset of symptoms is insidious so that 38 COPD is frequently under-diagnosed and, when diagnosed, this is often late with severe respiratory 39 disorders. $^{2}$ Overwhelming interest in smoking as the major risk factor has overshadowed the 40 importance of non-smoking causes, ${ }^{3}$ such as occupational exposure (including farming activities). ${ }^{4-6}$

41 Although spirometry is the reference test for diagnosing COPD, it is not a cost-effective way to 42 screen the general population. ${ }^{7}$ A promising alternative is low-cost electronic mini-spirometry (EMS) 43 measuring the $\mathrm{FEV}_{1} / \mathrm{FEV}_{6}$ ratio but its diagnostic performance depends very much on how well 44 practitioners are trained. ${ }^{8}$ Previous studies have suggested using self-administered questionnaires to 45 screen for COPD. ${ }^{9-11}$ The COPD Assessment Test (CAT) was initially developed and validated for 46 routinely assessing and monitoring COPD patients. ${ }^{12-13}$ It was later used to help screen for COPD in 47 both smokers, ${ }^{14-15}$ and the general population. ${ }^{16-17}$ Subjects who the CAT questionnaire indicated were 48 at risk then underwent diagnostic spirometry and appropriate medical management, if necessary, 49 before any severe symptoms developed. However, the CAT questionnaire has not yet been used to 50 screen farmers for COPD, who are often slow or reluctant to seek health care.

51 We therefore assessed the value of the CAT questionnaire for screening a large population of dairy 52 farmers for COPD and for developing a predictive model that combines CAT scores with other COPD 53 predictors.

\section{2. MATERIALS AND METHODS}

\section{$57 \quad 2.1$ Study population}

58

59 The AIRBAg cross-sectional study was conducted between March 2012 and February 2017 in the 60 French region of Brittany to determine the prevalence and to identify the risk factors of COPD in 61 dairy farmers. ${ }^{18}$ It was carried out on 2089 dairy farmers randomly selected from the 3831 registered 62 in the "Mutualité Sociale Agricole" (MSA, French Health Insurance for farmers) regional database. 63 The inclusion criteria were: dairy farming for more than ten years and agreeing to participate in the 64 study. The exclusion criteria were: pig, poultry or agricultural farming as the main activity, having a 65 legal guardian, having had a respiratory infection in the two months immediately preceding sampling, 66 having been treated with oral corticosteroids or immunosuppressive drugs, having been pregnant or 67 not having had any dairy activity for more than five years (e.g. retired). 
71 Each randomly selected dairy farmer was invited to complete a standardized self-administered 72 questionnaire and to undergo a health check-up with his/her local MSA occupational physician. 73 During this check-up, the questionnaire was reviewed and a clinical examination, followed by an 74 EMS and conventional spirometry, was performed. The first part of the questionnaire contained items 75 pertaining to health outcomes including: chronic cough (cough $>2$ months), chronic bronchitis (cough 76 and sputum > 3 months/year for over two consecutive years) and wheezing when handling hay or 77 during any other activity. The second part of the questionnaire collected farm and occupational 78 characteristics such as farm size, numbers of cattle and milking cows, crops grown and daily activities 79 (milking, production and distribution of feed concentrate, free stall mulching, etc.). CAT and the 80 modified Medical Research Council (mMRC) scores were also assessed during this check-up. The 81 CAT questionnaire consists of 8 items (cough, phlegm, chest tightness, breathlessness, activity 82 limitation, confidence leaving home, sleep, energy) with scores of 0-5 for the severity of each item. 83 These were then summed to give an overall score ranging from 0 (excellent perceived health) to 40 84 (worst case).

85

\section{$86 \quad 2.3$ Respiratory tests performed by occupational physicians}

87

88 The occupational physicians had been trained to use the EMS (Neo- $6^{\circledR}$, model 4000, Vitalograph, 89 Ennis, Ireland) and the spirometer (SpiroWin ${ }^{\circledR}$, FIM medical, Spl10 USB S/N:01824, Villeurbanne, 90 France), which was followed by annual updating. Spirometry testing (without bronchodilator 91 challenge) was performed in accordance with standard American Thoracic Society/European 92 Respiratory Society protocol. ${ }^{19}$ A minimum of three blows that met test quality criteria (including an 93 expiration maintained for more than $6 \mathrm{~s}$ ) were performed by each participant. Spirometry results were 94 reviewed by two pulmonologists from Rennes University Hospital.

962.4 Definition of COPD and absence of bronchial obstruction

97

98 Those subjects whose health check-up revealed at least one evocative symptom (chronic cough, 99 chronic bronchitis, wheezing, dyspnea $[\mathrm{mMRC} \geq 1]$ ) and/or a ratio $\mathrm{FEV}_{1} / \mathrm{FEV}_{6}<80 \%$ with the EMS 100 were considered to be "at-risk of bronchial obstruction". A higher cut-off was chosen for $\mathrm{FEV}_{1} / \mathrm{FEV}_{6}$ 101 because mild forms of limited airflow can be missed using a 70\% cut-off. ${ }^{20}$ "At-risk" farmers were 102 referred to the nearest pulmonologist for further examination, including spirometry with a reversibility 103 test. COPD was diagnosed if the post-bronchodilator $\mathrm{FEV}_{1}$ / forced vital capacity (FVC) ratio was $104<70 \%$ (GOLD criterion). ${ }^{21}$ The control population was farmers not "at-risk" and those "at-risk" at 105 screening who were subsequently not found to be suffering from a chronic obstructive disease and 
were assumed to be free of bronchial obstruction. Any control subject diagnosed with asthma was

107 excluded from the current study. Asthma was ascertained after a thorough medical record review by

108 the same trained pulmonologist by means of history of allergic disposition, episodes of paroxysmal

109 wheezing, asthma medication use, spirometry, and/or methacholine challenge test.

1112.5 Statistical analyses

112

113 A logistic regression model containing only the CAT sum score as predictor was first prepared

114 (univariate model). Other independent COPD predictors were then selected according to a two-step 115 strategy: i) the candidate covariates collected during the occupational health check-up (questionnaire, 116 mMRC) were selected at $\mathrm{p}<0.20$ on the basis of relevant univariate tests, ii) a bootstrap method was

117 then used to identify the best subset of independent predictors of COPD. This was done by repeated 118 sampling with replacement from the original entire dataset, followed by stepwise logistic regression 119 based on Akaike's Information Criterion in each of 1000 subsamples. The decision rule for selecting 120 the predictors included in the final model is based on the frequency at which they appeared in the 121 multiple bootstrap models (> $60 \%$ in our study, as recommended ${ }^{22}$ ). Continuous variables were not 122 transformed if they were found to be linear. Subjects were divided into two groups according to their 123 body mass index (BMI): above or below $21 \mathrm{~kg} / \mathrm{m}^{2}$, as in the BODE mortality index. ${ }^{23-24}$ The 124 diagnostic performance of the univariate and multivariate models was assessed by measuring the area 125 under the receiver operating characteristic curve (AUC). However, a predictive model may be too 126 optimistic if it is tested on the same dataset as that used to develop it. We used a 1000-fold bootstrap 127 resampling including the previously selected predictors to obtain optimism-corrected AUCs. An 128 optimal cut-off point was determined to obtain the best sensitivity by minimizing the number of false 129 negatives.

130 The second step involved building a decision tree with the predictors from the previous 131 multivariate model using the Classification And Regression Tree (CART) method. ${ }^{25}$ Briefly, CART 132 uses successive iterations to divide the study sample into smaller binary subgroups. Each step 133 investigates all possible splits among the variables to create two subgroups. The variable with the 134 optimal threshold leading to the most homogeneous partitioning with respect to the dependent 135 variable (COPD in the current study) is selected. The same variable can be chosen several times, 136 based on different thresholds because all predictors are considered at each step. Decision trees are 137 sensitive to the imbalance in the numbers of events and non-events. A weighting of misclassified 138 subjects (false positives and negatives) was thus used to improve sensitivity. False negatives and false 139 positives were each weighted by the inverse of the frequencies of events and non-events in the 140 sample.

141 The predictive model and CART analyses were first prepared with the CAT sum score and then 142 with each of the CAT items most strongly linked to COPD $(P<0.05)$. All statistical analyses were 
143 performed with R software, version 3.5.0 (R Foundation for Statistical Computing, Vienna, Austria,

144 URL https://www.R-project.org/).

146 3. RESULTS

147

\section{$148 \quad 3.1$ Population}

149

150 The 1231 farmers who underwent the occupational health check-up included 28 who met an exclusion

151 criterion (poultry farmer (5); pig farmer (5); arable farmer (1); recent treatment with antibiotics or

152 corticosteroids (7); immunosuppressive treatment (4); no signed consent (1); incomplete questionnaire

153 (5)), leaving 1203 for analyses (Figure 1). The occupational health check-up showed that 525 farmers

154 were "at-risk of bronchial obstruction", of these 432 were seen by the pulmonologist. The 93 farmers

155 who did not go to the pulmonologist included a greater proportion of smokers (23.7\%), a lower

$156 \mathrm{FEV}_{1} / \mathrm{FVC}$ ratio (0.76) and had spent more time on-farm (47.4 years) than the 432 who were seen by

157 the pulmonologist $(13.7 \%, P=0.01 ; 0.78, P<0.01 ; 44.3$ years, $P<0.01$ ).

158 Pulmonologist identified 16 cases of COPD (1.3\%), eight of whom (50\%) were non-smokers.

159 None of these subjects were known to be ill prior to the study. The mean standard spirometry test data

160 were: $\mathrm{FEV}_{1} / \mathrm{FVC}$ ratio $=0.66( \pm 0.09), \mathrm{FEV}_{1}=2.52( \pm 1.02) \mathrm{L}$ and $83.6( \pm 2.9) \%$ of predicted values.

161 The distribution of the disease severity according to GOLD classification was: GOLD I = 11 subjects,

162 GOLD II = 4, GOLD III = 1 .

163 The final bronchial obstruction-free group consisted of $996(673+323)$ farmers: 107 were excluded 164 because they were asthmatic (9+93 in the "at-risk" group and 5 in the not "at-risk" group) (Figure 1).

165 None of the 107 asthma cases had obstruction on spirometry.

166 The farmers with COPD were significantly older (54.6 years), had spent more time on-farm (51.4 167 years) and in dairying (33.8 years, and more were current smokers (37.5\%) than the controls (50.8 168 years, $P=0.02 ; 44.3$ years, $P<0.01 ; 27.8$ years, $P=0.01 ; 10.2 \%, P=0.02$ ) (Table 1$)$. The COPD 169 farmers had a higher CAT sum score (9.6 \pm 6.2$)$ than the controls $(6.2 \pm 4.5)$ and higher scores for the 170 four main items (cough, phlegm, chest tightness, breathlessness) (Table 2).

$172 \quad 3.2$ COPD predictive models

174 The univariate logistic regression model constructed with the CAT sum score provided an AUC of 1750.68 (95\% confidence interval [CI]: 0.53-0.83). The independent predictors of COPD introduced into 176 the multivariate model were: time spent on-farm (continuous variable, in years), BMI $(\leq$ or $>21$ $177 \mathrm{~kg} / \mathrm{m}^{2}$ ), smoking status (non-smoker, former smoker, current smoker), free-stall mulching (yes/no). 178 The corresponding risk estimates are shown in Table 3. The AUC of this multivariate model was 0.87 
180 a sensitivity of $93.8 \%$, and a specificity of $62.4 \%$. The ROC curves of the univariate and multivariate 181 predictive models are shown in Figure 2. One COPD farmer was misclassified with the multivariate 182 model: his CAT sum score was 3, he was a non-smoking 44-year-old farmer, had spent 33 years on183 farm, had a BMI of $23.9 \mathrm{~kg} / \mathrm{m}^{2}$ and reported performing free-stall mulching.

184 The predictive performances of the models including each of the four CAT items most strongly 185 associated with COPD (cough, phlegm, chest tightness, breathlessness) are shown in Table 4. 186 Independent COPD predictors were the same as those identified for the CAT sum score model 187 whatever the single CAT item model. The only multivariate regression model which performed 188 marginally better than the CAT sum score model involved breathlessness (AUC $=0.88$ (95\% CI: $1890.77-0.98), \mathrm{cAUC}=0.84$, sensitivity $=93.8 \%$ and specificity $=76.1 \%$, for a cut-off of 0.013 ).

\section{$191 \quad 3.3$ Decision trees}

192

193 The root node of the decision tree constructed with the CAT sum score was the CAT sum score itself 194 with a cut-off value of 11 (Figure 3). Two COPD cases were misclassified traversing the tree (CAT 195 sum score $<11, \mathrm{BMI}>21 \mathrm{~kg} / \mathrm{m}^{2}$ and time spent on-farm $<57$ years, sensitivity $\left.=87.5 \%(14 / 16)\right)$. The 196 CART model relying on breathlessness was simpler (3 splits instead of 5 splits) and misclassified only 197 one case (sensitivity $=93.8 \%(1 / 16)$ ) (Figure 4). The three main splits in the "breathlessness" model 198 were current smoker: yes / no; years spent on-farm: $<60 / \geq 60$; breathlessness: $<2 / \geq 2$ ).

\section{4. DISCUSSION}

202

203 Our model that combines the CAT sum score and four independent predictors (time spent on-farm,

204 BMI, smoking status, free-stall mulching) is a highly sensitive and reasonably specific tool for 205 screening dairy farmers for COPD.

206 The main strength of the AIRBAg study is its robust methodology based on a large randomly-

207 selected sample of dairy farmers. The comprehensive questionnaire completed during the

208 occupational health visit contained many variables, some specific to dairy farming, which make it 209 possible to test many potential predictors of COPD. COPD was diagnosed using a spirometry 210 reference test rather than the mini-spirometry employed in most similar studies. ${ }^{14-15}$ No COPD-asthma 211 overlap was to be feared because asthma cases had no evidence of obstructive spirometry. Finally, we 212 used a sound statistical methodology based on bootstrap resampling to select the best subset of 213 independent covariates and to adjust for overfitting. 
But this study has some limitations. First, over one-fifth $(21.6 \%$; 451/2089) of the farmers refused

215 to undergo the occupational health check-up and 17.7\% (93/525) of those who were "at risk of

216 bronchial obstruction" did not visit the pulmonologist. Cases of COPD may thus have been missed. In

217 addition, the 93 subjects who did not visit the pulmonologist included a greater proportion of smokers

$218(23.7 \%)$ than the 432 who did (13.7\%). Finally, the relatively few cases (16) may not have provided

219 the statistical power needed to identify other predictive factors of COPD. However, this study also

220 identified the basic predictors highlighted in other similar studies (age and smoking). As the number

221 of subjects was too small for the sample to be divided into learning and validation datasets we used an

222 internal bootstrap validation rather than a cross validation approach.

223 Early detection of COPD is essential because cases of even mild COPD are at increased risk of

224 death. ${ }^{26}$ While the diagnostic performance of EMS, developed as a screening solution, is good in a

225 primary care setting, its use requires physician training for it to be reliable. ${ }^{8}$ In contrast, the CAT

226 questionnaire can be completed by the subject him/her self before the medical examination. Various

227 questionnaires that screen for COPD in the general population have been developed, ${ }^{9-11}$ but the

228 advantage of the CAT questionnaire is its dual screening and monitoring function, which enables

229 patients to be followed-up.

230 Previous studies on other populations have assessed the performance of the CAT questionnaire for

231 COPD screening. A Japanese study on 3062 smokers over 40 years old who consulted for repeated

232 respiratory infections or to monitor their cardiovascular disease found that the CAT sum score was

233 significantly higher in those with airflow limitation. ${ }^{14}$ A study in Turkey of 648 smokers over 40 years

234 old who went to a university hospital for a check-up or visit found that the variables associated with

235 COPD were age, smoking (number of pack-years) and the CAT sum score. ${ }^{15}$ The first four CAT items

236 were also significantly associated with COPD. The AUC obtained with the CAT sum score alone was

237 similar to that reported here (0.61). A Canadian population-based study of 532 subjects over 40

238 confirmed the value of the CAT scores for defining "at-risk" subjects. ${ }^{16}$ The CAT sum score

239 performed well and the breathlessness score performed even better (although not as well as in the

240 present study). The AUC with the predictive model including breathlessness, age and smoking status

241 was 0.77 ; sensitivity was $77.6 \%$ and specificity was $64.9 \%$ with a cut-off of 0.096 .

242 The present model contains five variables, making it slightly more complex than the three-variable

243 one constructed by Raghavan et al. ${ }^{16}$ However, the predictive performance of our model for dairy

244 farmers is better (cAUC $=0.83$, sensitivity $=93.8 \%$, specificity $=62.4 \%$ ), with only one subject

245 misclassified. Logically, it includes the smoking status of the subjects, an influential risk factor.

246 Consistent with many previous studies, ${ }^{27-32}$ we found a negative association between BMI and COPD

247 (while adjusting for other confounding factors). However, the observed relationship may not be causal

248 as COPD prevalence (and not incidence) was recorded in this cross-sectional study.

249 Age was not included in the multivariate selection, but the on-farm time was, suggesting that

250 agricultural exposure plays a role in COPD occurrence. Many farming tasks, such as handling hay 
251 (during feeding), straw and animal feed, expose farmers to airborne contaminants and dust. ${ }^{33-34}$ This

252 exposure could trigger inflammatory reactions leading to the development of COPD. Finally, and

253 somewhat paradoxically, the absence of free stall mulching was predictive of COPD. Further analyses

254 showed that farmers who did not do this mulching generally performed fewer other agricultural

255 activities (results not shown). This negative association could then be also explained by a reverse

256 causal effect, as the disease at its preclinical phase may limit or hinder the execution of burdensome

257 tasks. Finally, in-depth item analyses highlighted how "breathlessness" improved the screening for

258 COPD in dairy farmers (as evidenced by a marginally increased AUC, due to a better specificity), in

259 agreement with the growing evidence showing that even subjects in the early stages of COPD

260 experience dyspnea with exertion. ${ }^{35-38}$

261 A CART analysis provides simple decision rules that are easy for physicians to use. The

262 "breathlessness" based decision tree has the double advantage of being simpler and more sensitive

263 than the "CAT sum score" tree. However, it would avoid less diagnostic spirometries (those non-

264 performed in farmers predicted not at risk of COPD) than the "CAT sum score" tree, as assessed by

265 the denominators of solid line ovals in Figures 3 and 4 (589 and 697+42+43=782, respectively).

266 In conclusion, the predictive performance of a model that includes the CAT sum score (or even

267 only the breathlessness score), obtained from an easy-to-use questionnaire in current practice, plus

268 four other predictors that are also readily collected during an interview (smoking status, on-farm time,

269 type of farming activity) or an elementary clinical examination (BMI) was good when used to assess a

270 population of dairy farmers. We therefore believe that this combination provides a simple, low-cost

271 on-site tool for screening them for COPD. It would both benefit farmers by providing early diagnosis

272 and management of their disease and avoid unnecessary, costly spirometry.

273 


\section{ACKNOWLEDGEMENTS}

We are indebted to all the dairy farmers who took part in the screening test and completed the respiratory investigation. We thank Dr Owen Parkes for editing the manuscript.

\section{FUNDING}

The AIRBag study was supported by Rennes University Hospital (COREC 2011 funding), the "Association pour les insuffisants respiratoires de Bretagne" (AIRB), the French Ministry of Labour (DIRECCTE), and Novartis Pharma (France). The sponsors played no role in the design, collection, analysis or interpretation of the data, in writing the manuscript or in the decision to submit the manuscript for publication.

\section{ETHICS}

The AIRBAg study was approved by the Rennes Ouest V Ethics Committee (11/28-817) and was registered on ClinicalTrials.gov (NCT03654469). Written informed consent was provided by all participants. 


\section{REFERENCES}

1. Mathers CD, Loncar D. Projections of global mortality and burden of disease from 2002 to 2030. PLOS Med. 2006;3: e442.

2. Soriano JB, Zielinski J, Price D. Screening for and early detection of chronic obstructive pulmonary disease. Lancet. 2009;374:721-32.

3. Lamprecht B, McBurnie MA, Vollmer WM, Gudmundsson G, Welte T, NizankowskaMogilnicka E, Studnicka M, Bateman E, Anto JM, Burney P, Mannino DM, Buist SA. COPD in Never Smokers, Results from the population-based burden of obstructive lung disease study. Chest. 2011;139:752-63.

4. Lamprecht B, Schirnhofer L, Kaiser B, Studnicka M, Buist AS. Farming and the prevalence of non-reversible airways obstruction: results from a population-based study. Am J Ind Med. 2007;50:421-6.

5. Blanc PD, Menezes AMB, Plana E, Mannino DM, Hallal PC, Toren K, Eisner MD, Zock JP. Occupational exposures and COPD: an ecological analysis of international data. Eur Respir J. 2009;33:298-304.

6. Eduard W, Pearce N, Douwes J. Chronic bronchitis, COPD, and lung function in farmers: the role of biological agents. Chest. 2009;136:716-25.

7. U.S. Preventive Services Task Force. Screening for chronic obstructive pulmonary disease using spirometry: U.S. Preventive Services Task Force recommendation statement. Ann Intern Med. 2008;148:529-34.

8. Perez T, Bizon C. Mini-spirometry: A relevant tool for the screening of COPD in general practice? [in French] Rev Mal Respir. 2012;29: 853-5.

9. Martinez FM, Raczek AE, Seifer FD, Conoscenti CS, Curtice TG, D’Eletto T, Cote C, Hawkins C, Phillips AL. COPD-PS Clinician Working Group, Development and initial validation of a self-scored COPD population screener questionnaire (COPD-PS). COPD. 2008;5:85-95.

10. Yawn BP, Mapel DW, Mannino DM, Martinez FJ, Donohue JF, Hanania NA, Kosinski M, Rendas-Baum R, Mintz M, Samuels S, Dalal AA. Lung Function Questionnaire Working Group, Development of the Lung Function Questionnaire (LFQ) to identify airflow obstruction. Int J Chron ObstrucT Pulmon Dis. 2010;5:1-10.

11. Weiss G, Steinacher I, Lamprecht B, Kaiser B, Mikes R, Sator L, Hartl S, Wagner H, Studnicka M. Development and validation of the Salzburg COPD-screening questionnaire (SCSQ): a questionnaire development and validation study. NPJ Prim Care Respir Med. 2017;27:4.

12. Jones P, Harding G, Wiklund I, Berry P, Leidy N. Improving the process and outcome of care in COPD: development of a standardised assessment tool. Prim Care Respir J. 2009;18:208-15.

13. Jones PW, Harding G, Berry P, Wiklund I, Chen WH, Leidy NK. Development and first validation of the COPD Assessment Test. Eur Respir J. 2009;34:648-54. 
14. Yoshimoto D, Nakano Y, Onishi K, Hagan G, Jones P. The relationship between the COPD Assessment Test score and airflow limitation in Japan in patients aged over 40 years with a smoking history. Int J Chron Obstruct Pulmon Dis. 2014;9:1357-63.

15. Kart L, Akkoyunlu ME, Bayram M, Yakar F, Özçelik HK, Karaköse F, Sezer M. COPD: an underdiagnosed disease at hospital environment. Wien Klin Wochenschr. 2014;126:73-8.

16. Raghavan N, Lam YM, Webb KA, Guenette JA, Amornputtisathaporn N, Raghavan R, Tan WC, Bourbeau J, O’Donnell DE. Components of the COPD Assessment Test (CAT) associated with a diagnosis of COPD in a random population sample. COPD. 2012;9:175-83.

17. Jones PW, Shahrour N, Nejjari C, Lahlou A, Doble A, Rashid N, El Hasnaoui A. BREATHE Study Group, Psychometric evaluation of the COPD assessment test: data from the BREATHE study in the Middle East and North Africa region. Respir Med. 2012.106 Suppl 2:S86-99.

18. Jouneau S, Marette S, Robert AM, Gouyet T, Guillot S, Chapron A, Mailloux C, Desrues B, Viel JF. Prevalence and risk factors of chronic obstructive pulmonary disease in dairy farmers: AIRBAg study. Environ Res. 2019;169:1-6.

19. Miller MR, Hankinson J, Brusasco V, Burgos F, Casaburi R, Coates A, Crapo R, Enright P, van der Grinten CPM, Gustafsson P, Jensen R, Johnson DC, MacIntyre N, McKay R, Navajas D, Pedersen OF, Pellegrino R, Viegi G, Wanger J. Standardisation of spirometry. Eur Respir J. 2005;26:319-38.

20. Vandevoorde J, Verbanck S, Schuermans D, Kartounian J, Wincken W. Obstructive and restrictive spirometric patterns: fixed cut-offs for FEV1/FEV6 and FEV6. Eur Respir J. 2006;27: 378-83.

21. Vollmer WM, Gíslason T, Burney P, Enright PL, Gulsvik A, Kocabas A, Buist AS. Comparison of spirometry criteria for the diagnosis of COPD: results from the BOLD study. Eur Respir J. 2009;34:588-97.

22. Austin PC, Tu JV. Bootstrap methods for developing predictive models. Am Stat. 2004;58:1317.

23. Celli BR, Cote CG, Marin JM, Casanova C, Montes de Oca M, Mendez RA, Pinto Plata V, Cabral HJ. The body-mass index, airflow obstruction, dyspnea, and exercise capacity index in chronic obstructive pulmonary disease. N Engl J Med. 2004;350:1005-12.

24. Roberts MH, Mapel DW, Bruse S, Petersen H, Nyunoya T. Development of a modified BODE index as a mortality risk measure among older adults with and without chronic obstructive pulmonary disease. Am J Epidemiol. 2013;178:1150-60.

25. Breiman L, Friedman J, Olshen RA, Stone CJ. Classification and regression trees. Wadsworth, Belmont: Chapman and Hall/CRC; 1984.

26. Mannino DM, Buist AS, Vollmer WM. Chronic obstructive pulmonary disease in the older adult: what defines abnormal lung function? Thorax. 2007;62:237-41. 
27. Harik Khan RI, Fleg JL, Wise RA. Body mass index and the risk of COPD. Chest. 2002;121:370 $-6$.

28. Zhou Y, Wang D, Liu S, Lu J, Zheng J, Zhong N, Ran P. The association between BMI and COPD: the results of two population-based studies in Guangzhou, China. COPD J Chronic Obstr Pulm Dis. 2013;10:567-72.

29. Smith M, Li L, Augustyn M, Kurmi O, Chen J, Collins R, Guo Y, Han Y, Qin J, Xu G, Wang J, Bian Z, Zhou G, Peto R, Chen Z. Prevalence and correlates of airflow obstruction in 317000 never-smokers in China. Eur Respir J. 2014;44:66-77.

30. Lee SJ, Chang JH, Kim SW, Kong KA, Ryu YJ, Lee JH. Risk factors for chronic obstructive pulmonary disease among never-smokers in Korea. Int J Chron Obstruct Pulmon Dis. 2015;497506.

31. Wang C, Xu J, Yang L, Xu Y, Zhang X, Bai C, Kang J, Ran P, Shen H, Wen F, Huang K, Yao W, Sun T, Shan G, Yang T, Lin Y, Wu S, Zhu J, Wang R, Shi Z, Zhao J, Ye X, Song Y, Wang Q, Zhou Y, Ding L, Yang T, Chen Y, Guo Y, Xiao F, Lu Y, Peng X, Zhang B, Xiao D, Chen CS, Wang Z, Zhang H, Bu X, Zhang X, An L, Zhang S, Cao Z, Zhan Q, Yang Y, Cao B, Dai H, Liang L, He J. Prevalence and risk factors of chronic obstructive pulmonary disease in China (the China Pulmonary Health [CPH] study): a national cross-sectional study. The Lancet. 2018;391:1706-17.

32. Li J, Zhu L, Wei Y, Lv J, Guo Y, Bian Z, Du H, Yang L, Chen Y, Zhou Y, Gao R, Chen J, Chen $\mathrm{Z}$, Cao W, Yu 1, Li L. Association between adiposity measures and COPD risk in Chinese adults. Eur Respir J. 2020; in press.

33. von Essen SG, Banks DE. Life-long exposures on the farm, respiratory symptoms, and lung function decline. Chest. 2009;136:662-3.

34. Thaon I, Thiebaut A, Jochault L, Lefebvre A, Laplante JJ, Dalphin JC. Influence of hay and animal feed exposure on respiratory status: a longitudinal study. Eur Respir J. 2011;37:767-74.

35. Ofir D, Laveneziana P, Webb KA, Lam YM, O'Donnell DE. Mechanisms of dyspnea during cycle exercise in symptomatic patients with GOLD stage I chronic obstructive pulmonary disease. Am J Respir Crit Care Med. 2008;177:622-9.

36. O’Donnell DE, Laveneziana P, Ora J, Webb KA, Lam YM, Ofir D. Evaluation of acute bronchodilator reversibility in patients with symptoms of GOLD stage I COPD. Thorax. 2009;64:216-23. 
37. Guenette JA, Jensen D, Webb KA, Ofir D, Raghavan N, O'Donnell DE. Sex differences in exertional dyspnea in patients with mild COPD: physiological mechanisms. Respir Physiol Neurobiol. 2011;177:218-27.

38. Neder JA, Berton DC, Müller PT, Elbehairy AF, Rocha A, Palange P, O’Donnell DE. Canadian Respiratory Research Network; Ventilatory inefficiency and exertional dyspnea in early chronic obstructive pulmonary disease. Ann Am Thorac Soc. 2017;14:S22-9. 
TABLE 1 Characteristics of farmers with COPD and farmers free of bronchial obstruction

\begin{tabular}{|c|c|c|c|c|}
\hline \multirow[b]{2}{*}{ Qualitative variable } & \multicolumn{2}{|c|}{$\begin{array}{l}\text { COPD } \\
(n=16)\end{array}$} & \multicolumn{2}{|c|}{$\begin{array}{c}\text { Bronchial } \\
\text { obstruction } \\
\text { free }(n=996)\end{array}$} \\
\hline & $\mathrm{n}$ & $\%$ & $\mathrm{n}$ & $\%$ \\
\hline Quantitative variable & $\mathrm{m}$ & $\pm \mathrm{SD}$ & $\mathrm{m}$ & $\pm \mathrm{SD}$ \\
\hline Age (years) & 54.6 & \pm 7.7 & 50.8 & \pm 6.5 \\
\hline On-farm time (years) & 51.4 & \pm 10.3 & 44.3 & \pm 11.7 \\
\hline \multicolumn{5}{|l|}{ Gender } \\
\hline Male & 10 & 62.5 & 717 & 72.0 \\
\hline Female & 6 & 37.5 & 279 & 28.0 \\
\hline \multicolumn{5}{|l|}{ BMI $\left(\mathrm{kg} / \mathrm{m}^{2}\right)$} \\
\hline$\leq 21$ & & 31.3 & 71 & 7.1 \\
\hline$>21$ & 11 & 68.7 & 925 & 92.9 \\
\hline \multicolumn{5}{|l|}{ Smoking status } \\
\hline Never & & 50.0 & 701 & 70.4 \\
\hline Former & & 12.5 & 193 & 19.4 \\
\hline Current & & 37.5 & 102 & 10.2 \\
\hline \multicolumn{5}{|l|}{ Farm characteristics } \\
\hline Area (Ha) & 83.5 & \pm 47.7 & 82.7 & \pm 42.9 \\
\hline Dairy farming activities (years) & 33.8 & \pm 9.6 & 27.8 & \pm 9.1 \\
\hline Milking cows (number) & 49.8 & \pm 24.6 & 51.7 & \pm 23.7 \\
\hline
\end{tabular}


TABLE 2 COPD assessment test (CAT) scores in dairy farmers with COPD and bronchial obstruction-free controls (Brittany, France, 2012-2017)

\begin{tabular}{|c|c|c|c|}
\hline & $\begin{array}{l}\text { COPD } \\
(n=16)\end{array}$ & $\begin{array}{l}\text { Bronchial } \\
\text { obstruction } \\
\text { free }(n=996)\end{array}$ & \multirow[t]{2}{*}{$P$ value } \\
\hline & $\mathrm{m} \pm \mathrm{SD}$ & $\mathrm{m} \pm \mathrm{SD}$ & \\
\hline Item 1: Cough & $1.8 \pm 0.8$ & $1.2 \pm 0.9$ & 0.02 \\
\hline Item 2: Phlegm & $1.4 \pm 1.2$ & $0.7 \pm 0.9$ & $<0.01$ \\
\hline Item 3: Chest tightness & $1.0 \pm 1.1$ & $0.5 \pm 0.7$ & 0.02 \\
\hline Item 4: Breathlessness & $1.8 \pm 1.3$ & $1.1 \pm 1.0$ & 0.03 \\
\hline Item 5: Activity limitation & $0.8 \pm 0.9$ & $0.5 \pm 0.8$ & 0.29 \\
\hline Item 6: Confidence leaving home & $0.4 \pm 0.8$ & $0.2 \pm 0.6$ & 0.22 \\
\hline Item 7: Sleep & $0.8 \pm 1.2$ & $0.7 \pm 0.9$ & 0.51 \\
\hline Item 8: Energy & $1.6 \pm 1.2$ & $1.2 \pm 1.0$ & 0.14 \\
\hline Sum score & $9.6 \pm 6.2$ & $6.2 \pm 4.5$ & $<0.01$ \\
\hline
\end{tabular}

Abbreviations: COPD: chronic obstructive pulmonary disease; m: mean; SD: standard deviation. 
TABLE 3 Odds ratio estimates for COPD in dairy farmers (n=993, multivariate model, Brittany, France, 2012-2017)

\begin{tabular}{|c|c|c|c|c|}
\hline & Odds ratio & & $5 \% \mathrm{CI}$ & $P$ value \\
\hline CAT sum score (unitless) & 1.12 & 1.02 & 1.21 & 0.02 \\
\hline On-farm time (years) & 1.11 & 1.05 & 1.19 & $<0.001$ \\
\hline $\mathrm{BMI} \leq 21 \mathrm{~kg} / \mathrm{m}^{2}$ & 12.93 & 3.43 & - 46.51 & $<0.001$ \\
\hline Smoking status & & & & $<0.01$ \\
\hline never & 1.00 & & - & - \\
\hline former & 1.36 & 0.19 & 6.15 & \\
\hline current & 12.12 & 3.35 & $-\quad 45.26$ & \\
\hline No free-stall mulching activity & 3.35 & 1.01 & - $\quad 10.50$ & 0.05 \\
\hline
\end{tabular}

Abbreviations: BMI: body mass index; CAT: COPD assessment test: CI, confidence interval; COPD: chronic obstructive pulmonary disease. 
TABLE 4 Predictive performance of multivariate models including either the CAT sum score or one of four CAT items (dairy farmers, Brittany, France, 2012-2017)

\begin{tabular}{lccccc} 
& AUC $(95 \% \mathrm{CI})$ & cAUC & Sensitivity & Specificity & Cut-off \\
\hline CAT sum score & $0.87(0.75-0.98)$ & 0.83 & $93.8 \%$ & $62.4 \%$ & 0.007 \\
Item 1: Cough & $0.86(0.75-0.97)$ & 0.82 & $93.8 \%$ & $63.4 \%$ & 0.008 \\
Item 2: Phlegm & $0.86(0.74-0.97)$ & 0.82 & $93.8 \%$ & $70.9 \%$ & 0.011 \\
Item 3: Chest tightness & $0.86(0.75-0.98)$ & 0.82 & $93.8 \%$ & $74.3 \%$ & 0.012 \\
Item 4: Breathlessness & $0.88(0.77-0.98)$ & 0.84 & $93.8 \%$ & $76.1 \%$ & 0.013
\end{tabular}

Abbreviations: CAT: chronic obstructive pulmonary disease assessment test; AUC: area under the receiver operating characteristic curve; cAUC: corrected AUC; CI: Confidence Interval. 
FIGURE 1 AIRBAg study flow chart (Brittany, France, 2012-2017)

Dairy farmers randomly selected and phone called $n=2089$

Refusal to participate $n=451$

Inclusion criteria not met $n=272$

Not available $n=135$

Exclusion criterion met $n=28$

Occupational health

check-up $n=1231$

Dairy farmers analysed $n=1203$

Asthma diagnosis in follow-up $n=5$

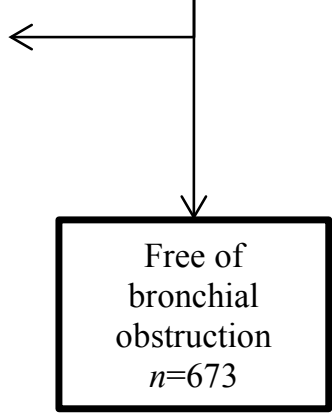

Population "at risk of bronchial obstruction"

$$
n=525
$$

Pulmonologist appointment $n=432$
Refusal to go to the pulmonologist (including 9 asthma diagnoses) $n=93$

Asthma diagnosis $n=93$

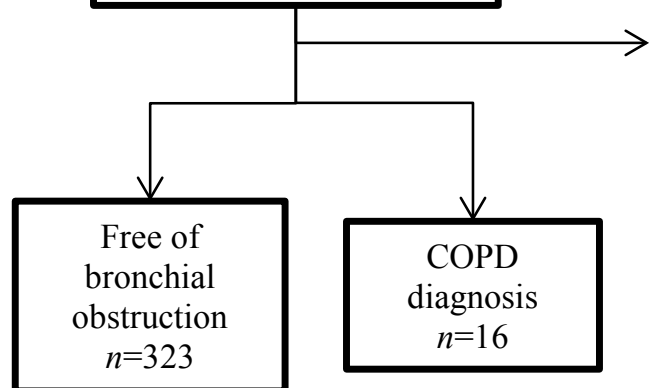


FIGURE 2 Receiver operating characteristic curves of predictive models for COPD (dairy farmers,

Brittany, France, 2012-2017)

Solid line: multivariate model, $\mathrm{AUC}=0.87,95 \%$ CI: $0.75-0.98$; dotted line: univariate model, AUC $=$ $0.68,95 \%$ CI: 0.53-0.83.

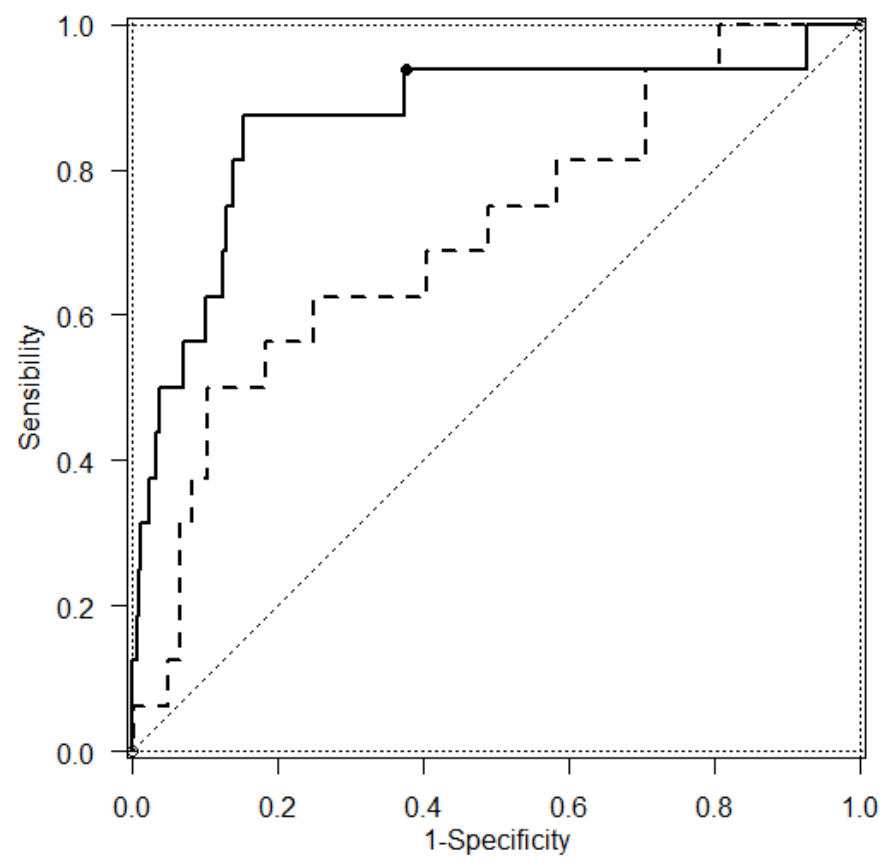


FIGURE 3 CART decision tree using the CAT sum score for predicting COPD in dairy farmers $(n=993$, Brittany, France, 2012-2017)

Solid line oval: farmers predicted not at-risk of COPD; dotted line oval: farmers predicted at-risk of COPD; COPD cases/group size.

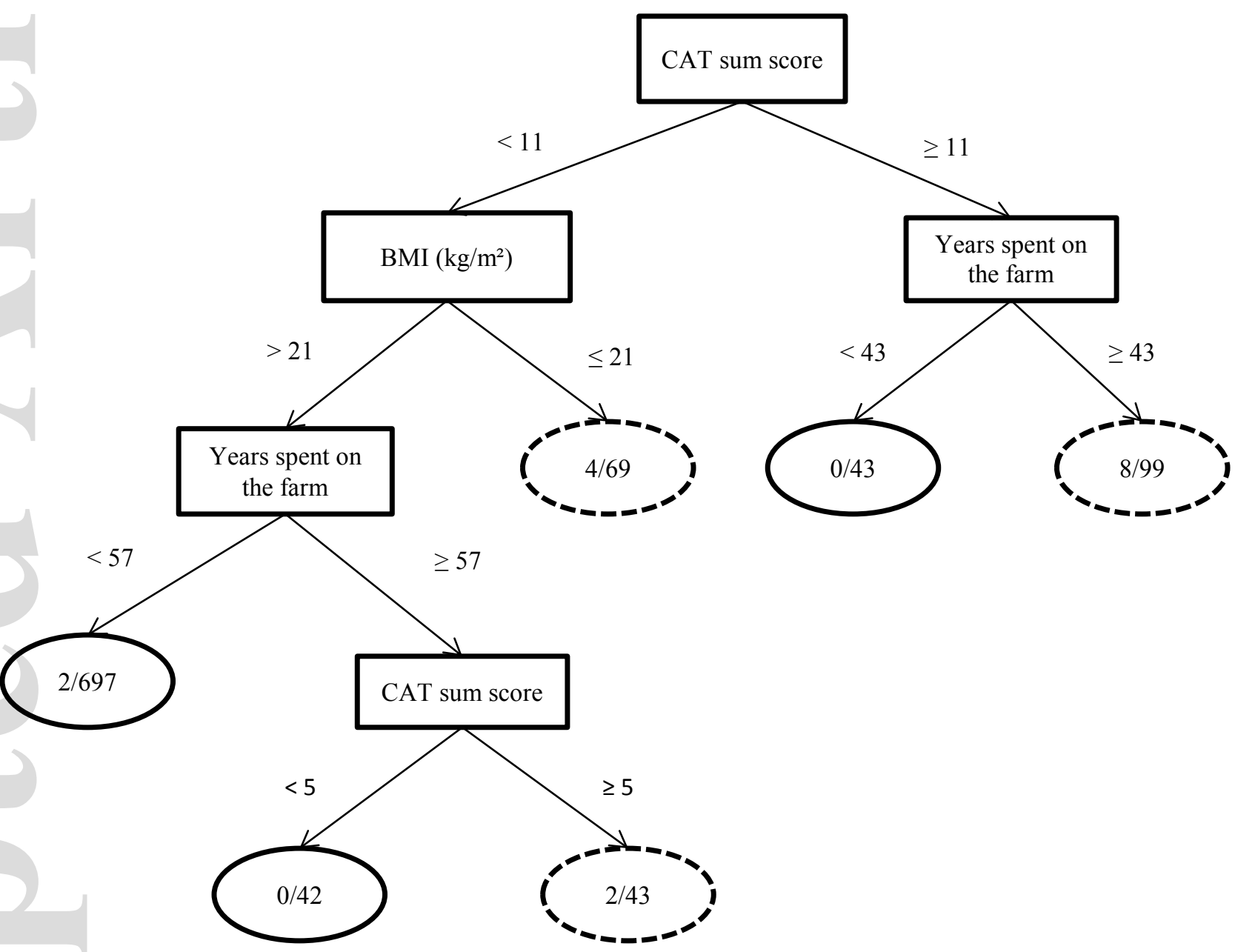


FIGURE 4 CART decision tree using the CAT breathlessness score for predicting COPD in dairy farmers ( $\mathrm{n}=1004$, Brittany, France, 2012-2017)

Solid line oval: farmers predicted not at-risk of COPD; dotted line oval: farmers predicted at-risk of COPD; COPD cases/group size.

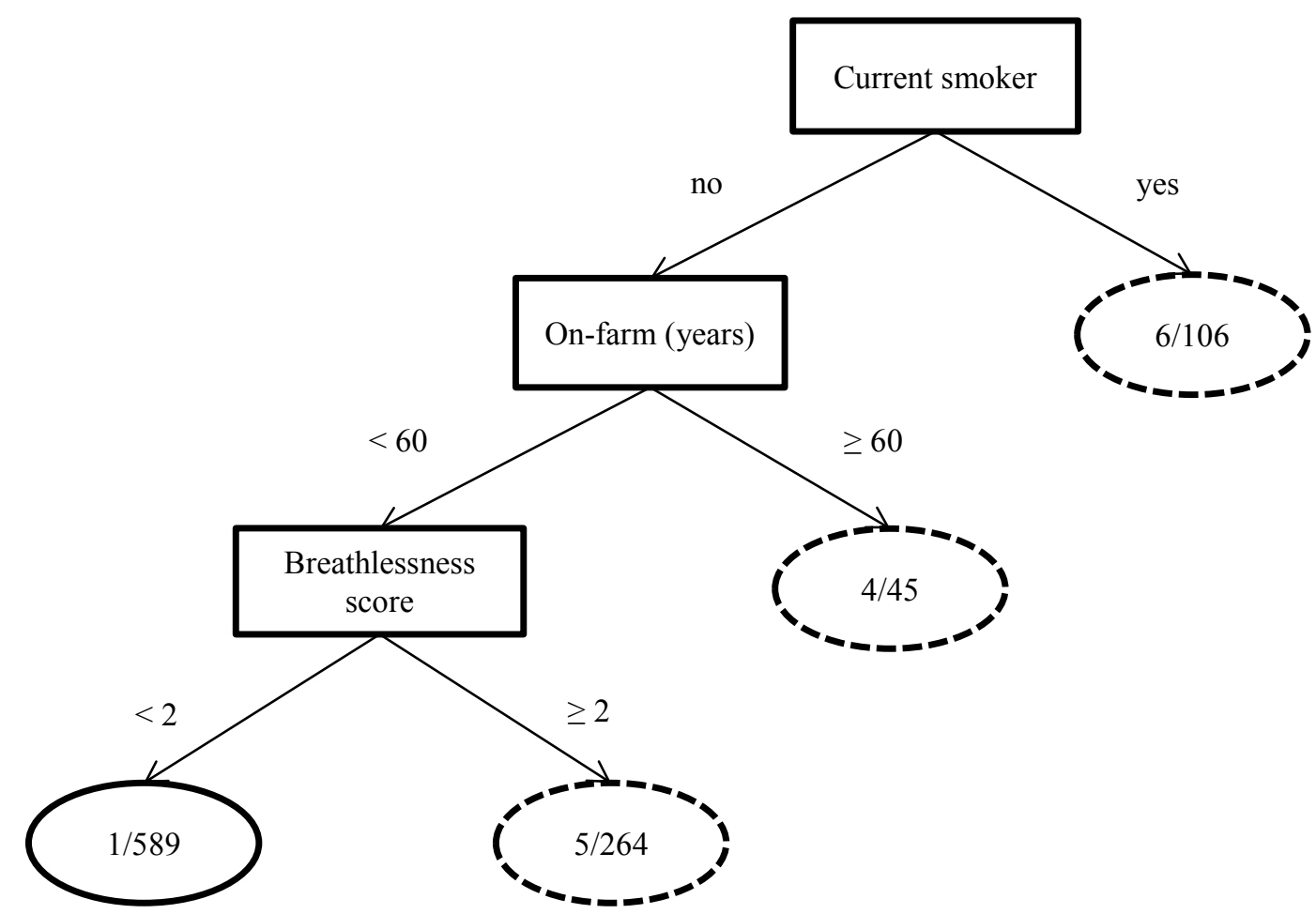

